\title{
Spot Urine Uric Acid to Creatinine Ratio used in the Estimation of Hyperuricosuria in the Young Korean Population
}

\author{
Hyowon Choi, M.D. \\ Meekyung Namgoong, M.D., Ph.D \\ Department of Pediatrics, Yonsei \\ University Wonju College of Medicine, \\ Wonju, Ganwon-do, Republic of Korea \\ Corresponding author: \\ Meekyung Namgoong, M.D., Ph.D. \\ Department of Pediatrics, Wonju \\ Severance Christian Hospital, 20, Ilsan- \\ ro, Wonju, Ganwondo, 26426, Republic of \\ Korea \\ Tel: +82-33-741-1282 \\ Fax: +82-33-732-6229 \\ E-mail:ngmk@yonsei.ac.kr
}

Received: 5 August 2021

Revised: 26 August 2021

Accepted: 26 September 2021
Background: Uric acid levels in urine are measured using urine specimens 24 hours or by uric acid glomerular filtration rate (UAGFR) with spot urine, which additionally requires a blood sample. This study aimed to investigate whether urinary uric acid creatinine ratio (UUACr) obtained by spot urine alone could be recognized as a substitute for UAGFR value, and hyperuricosuria can be screened by UUACr. UUACr is known to vary with age and regional differences. This study focused on the reference value of each value in Korean young populations.

Method: We enrolled Korean subjects 1-20 years with normal kidney function, from a single hospital, classified into 5 age groups, 1-5 years, $6-8$ years, 9-12 years, 13-15 years, and 16-20 years. We checked spot urine uric acid, creatinine and serum uric acid, creatinine levels on the same day from February 2014 to December 2018. We measured the average of UAGFR and UUACr in each groups. The UUACr cut-off value of the upper 2 standard deviation (SD) of UAGFR were taken.

Results: The upper 2 SD of UUACr $(\mathrm{mg} / \mathrm{mg})$ and UAGFR $(\mathrm{mg} / \mathrm{dL})$ were determined in all age groups. UUACr decreased with grown up $(P=0.000)$, but UAGFR were not statistically different among the groups. UUACr and UAGFR were not significantly different by gender. UUACr and UAGFR were positively correlated; UUACr cut-off value of upper 2 SD UAGFR $(0.54 \mathrm{mg} / \mathrm{dL})$ was $0.65 \mathrm{mg} / \mathrm{mg}$ in total age. Conclusions: UUACr could potentially be used to screen for hyperuricosuria.

Key words: Child, Glomerular filtration rate, Uric acid

\section{Introduction}

Evaluation of hyperuricosuria is often necessary in children with hematuria, urolithiasis, or dysuria to differentiate the underlying cause ${ }^{1-6)}$. Urine uric acid levels are tested by checking the 24 -hour urine uric acid value and using the uric acid glomerular filtration rate (UAGFR). For children inexperienced with urine control, collecting the 24-hour urine levels is difficult; furthermore, blood sampling is necessary to obtain blood creatinine for using the UAGFR value ${ }^{7,8)}$. Therefore, there is a need for a method that facilitates easy screening for hyperuricosuria in children.

The levels of all metabolites excreted in urine has high accuracy when the fluctuations in urine concentration are corrected with respect to the urine creatinine value. As the urinary creatinine value changes depending on the 
muscle mass or glomerular filtration rate (GFR), it can be said that the uric acid value is more accurate when corrected by GFR, and the value is known to be similar for all age groups ${ }^{8)}$. Additionally, according to previous studies, UUACr values vary by country and region, ${ }^{7,9-17)}$.

The purpose of this study was to compare GFR-corrected UAGFR with urinary uric acid creatinine ratio (UUACr), using only urine without a blood test, to see if it is possible to diagnose hyperuricosuria close to the standard UAGFR diagnostic value.. This study also aims to obtain a reference value of UUACr in Korean children and adolescents.

\section{Material and methods}

This study retrospectively enrolled children and adolescents under the age of 20 years who visited an outpatient clinic in South Korea for checkup between February 2014 and December 2018. This study protocol was approved by Institutional Review Boards (IRB) of Wonju Severance Christian hospital.

They are within normal blood pressure relative to their age and their weight and height are in 5-97\%. They underwent uric acid test. Those who consumed calcium and vitamin D nutritional supplements in the past 2 months were excluded from the study. The study subjects were classified based on age as 1-5 years, 6-8 years, 9-12 years, 1315 years, and 16-20 years, based on standard 6: age groups of pediatric research and yearly kidney development ${ }^{7,18)}$.

When they visited, we simultaneously conducted spot urine and blood sampling once for all enrolled patients. Urine collection bag was used for non-toilet trained patients, and midstream urine was used for toilet trained patients. We measured urine uric acid (UUA), urine creatinine (UCr) levels, conducted dipstick tests and microscopic assay. And also we measured serum creatinine (SCr), serum uric acid, and electrolyte levels. Uric acid and creatinine analyses were performed(Cobas 8000, C702, Roche, Swiss). As a result, UAGFR (mg/dL) and UUACr (mg/mg) levels were calculated. The value corrected for urinary uric acid excretion with GFR was UAGFR and was defined as UUA $(\mathrm{mg} / \mathrm{dL}) \times \mathrm{SCr}(\mathrm{mg} / \mathrm{dL}) / \mathrm{UCr}(\mathrm{mg} / \mathrm{dL})$. UUACr was defined as UUA (mg/dL)/UCr (mg/dL) ${ }^{6,7)}$. In addition, the upper 2 SD (standard deviation) value of UAGFR was de- fined as hyperuricosuria, and the UUACr value was calculated according to that value.

All statistical analyses were performed (SPSS 23.0). For comparison between males and females, the student t-test was used, while ANOVA analysis was used to compare the values between age groups. The association between UAGFR and UUACr was analyzed using linear regression, ROC (receiver operating characteristic) curve analysis was used in the process of finding the UUACr cut-off value for the upper 2 SD value of UAGFR. $P<0.05$ was considered statistically significant.

\section{Result}

In this retrospective study conducted with a total of 245 subjects, everyone had normal eGFR (Schwartz equation) and blood pressure. Among them, 6 had renal tubular disorders, 18 had glomerular diseases, 10 had ureter stone or hypercalciuria, 20 were taking vitamin D or calcium supplements, and 33 with proteinuria or hematuria were excluded from the study. A total of 168 people were enrolled with 98 men and 70 women.

In each age group, 31 patients from 1 to 5 years old (M:F= 17:14), 23 patients from 6 to 9 years old (M:F=9:14), 45 patients aged 9-12 years (M:F = 23:22), 37 patients aged 13-15 years $(\mathrm{M}: \mathrm{F}=25: 12)$, and 22 patients aged 16 years or older (M:F 18:4) (Fig. 1).

In the case of UUACr (mean $\pm D$ ), there was a significant difference among the age groups. The average value of the

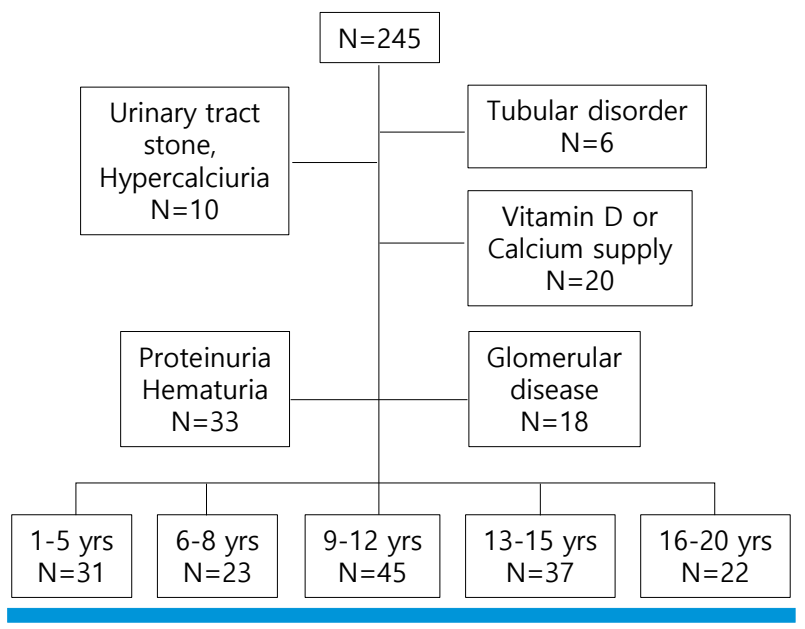

Fig. 1. Study population. 
entire group was $0.67 \pm 0.35 \mathrm{mg} / \mathrm{mg}$, and the values were $1.13 \pm 0.45 \mathrm{mg} / \mathrm{mg}, 0.73 \pm 0.18 \mathrm{mg} / \mathrm{mg}, 0.61 \pm 0.18 \mathrm{mg} / \mathrm{mg}$, $0.47 \pm 0.16 \mathrm{mg} / \mathrm{mg}$, and $0.40 \pm 0.13 \mathrm{mg} / \mathrm{mg}$ for the age groups $1-5$ years, $6-8$ years, 9-12 years, $13-15$ years, $16-20$ years, respectively. A decrease in the value with increasing age was noted $(P=0.000)$ (Table 1$)$.

For UAGFR (mean $\pm \mathrm{SD})$, the mean value of all subjects was $0.34 \pm 0.10 \mathrm{mg} / \mathrm{dL}$, and the values were $0.37 \pm 0.12 \mathrm{mg} /$ $\mathrm{dL}, 0.35 \pm 0.09 \mathrm{mg} / \mathrm{dL}, 0.34 \pm 0.09 \mathrm{mg} / \mathrm{dL}, 0.32 \pm 0.11 \mathrm{mg} / \mathrm{dL}$, and $0.32 \pm 0.10 \mathrm{mg} / \mathrm{dL}$ for the age groups $1-5$ years, $6-8$ years, 9-12 years, 13-15 years, 16-20 years, respectively, with no significant difference by age group $(P=0.080)$ (Table 1). Furthermore, there was no significant difference in UAGFR and UUACr between sexes within each age group (Table 1).

The UAGFR and UUACr of the total subjects had a positive proportional relationship $\left(P=0.0000, \mathrm{R}^{2}=0.426, \mathrm{y}=\right.$ 0.214+0.19x; y=UAGFR, $\mathrm{x}=\mathrm{UUACr}$ ) (Fig. 2).

When the upper 2 SD of the average UAGFR in the total group was defined as hyperuricosuria, because UAGFR values were not different by age group, the UUACr cut-off

Table 1. Urinary Uric Acid Creatinine Ratio (UUACr) and Urinary Uric Acid GFR

\begin{tabular}{|c|c|c|c|c|}
\hline \multirow{2}{*}{$\begin{array}{l}\text { Age group, } \\
\text { yr (n) }\end{array}$} & \multicolumn{2}{|c|}{$\operatorname{UUACr}(\mathrm{mg} / \mathrm{mg})$} & \multicolumn{2}{|c|}{ UAGFR (mg/dL) } \\
\hline & Mean $\pm S D$ & Mean+2SD & Mean \pm SD & Mean $+2 S D$ \\
\hline $1-5(31)$ & $1.13 \pm 0.45$ & 2.03 & $0.37 \pm 0.12$ & 0.61 \\
\hline$M(17)$ & $1.17 \pm 0.49$ & & $0.37 \pm 0.14$ & \\
\hline$F(14)$ & $1.08 \pm 0.43$ & & $0.37 \pm 0.87$ & \\
\hline $6-8(23)$ & $0.73 \pm 0.18$ & 1.09 & $0.35 \pm 0.09$ & 0.53 \\
\hline M (9) & $0.75 \pm 0.22$ & & $0.38 \pm 0.11$ & \\
\hline$F(14)$ & $0.72 \pm 0.14$ & & $0.34 \pm 0.08$ & \\
\hline $9-12(45)$ & $0.61 \pm 0.18$ & 0.97 & $0.34 \pm 0.09$ & 0.52 \\
\hline M (23) & $0.62 \pm 0.18$ & & $0.35 \pm 0.09$ & \\
\hline$F(22)$ & $0.59 \pm 0.19$ & & $0.32 \pm 0.09$ & \\
\hline $13-15(37)$ & $0.47 \pm 0.16$ & 0.79 & $0.32 \pm 0.11$ & 0.54 \\
\hline M (25) & $0.47 \pm 0.15$ & & $0.35 \pm 0.11$ & \\
\hline$F(12)$ & $0.47 \pm 0.17$ & & $0.28 \pm 0.08$ & \\
\hline $16-20(22)$ & $0.40 \pm 0.13$ & 0.66 & $0.32 \pm 0.10$ & 0.52 \\
\hline M (18) & $0.38 \pm 0.11$ & & $0.32 \pm 0.10$ & \\
\hline$F(4)$ & $0.49 \pm 0.18$ & & $0.34 \pm 0.13$ & \\
\hline Total (158) & $0.67 \pm 0.35$ & 1.37 & $0.34 \pm 0.10$ & 0.54 \\
\hline M (92) & $0.69 \pm 0.33$ & & $0.33 \pm 0.09$ & \\
\hline$F(66)$ & $0.64 \pm 0.37$ & & $0.35 \pm 0.11$ & \\
\hline
\end{tabular}

(UAGFR) across different age groups and sex.

aUUACr is significant different between age groups.

Abbreviations: GFR, glomerular filtration rate; M, male; F, female. value by ROC curve of the UAGFR $+2 \mathrm{SD}$ in all age was 0.651 , and sensitivity and specificity were $83.3 \%$ and $57.9 \%$ in total age group $(P=0.011,95 \%$ CI $0.688-0.983$, AUC 0.835 , Fig. 3). In each age group, $1-5$ yrs old d cut-off value was $1.52(P=0.064) .6-8 y$ rs old cut-off value was $1.10(P=$ 0.097). 13-15yrs old cut-off value was $0.62(P=0.070)$. There were no hyperuicosuria subject in 9-12yrs old group and

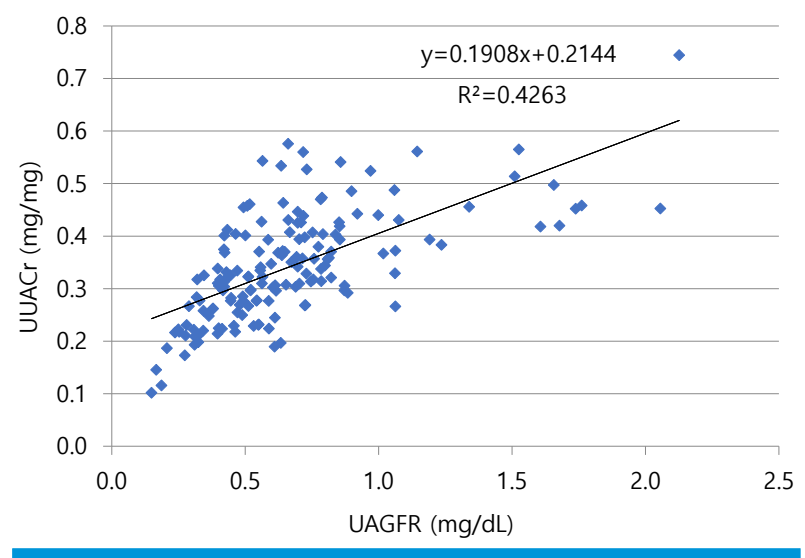

Fig. 2. Correlation between urinary uric acid creatinine ratio (UUACr) and urinary uric acid GFR (UAGFR) in all age groups ( $R=$ 0.602). $P=0.0000, y=0.2351+0.15 x, y=U A G F R, x=U U A C r$.

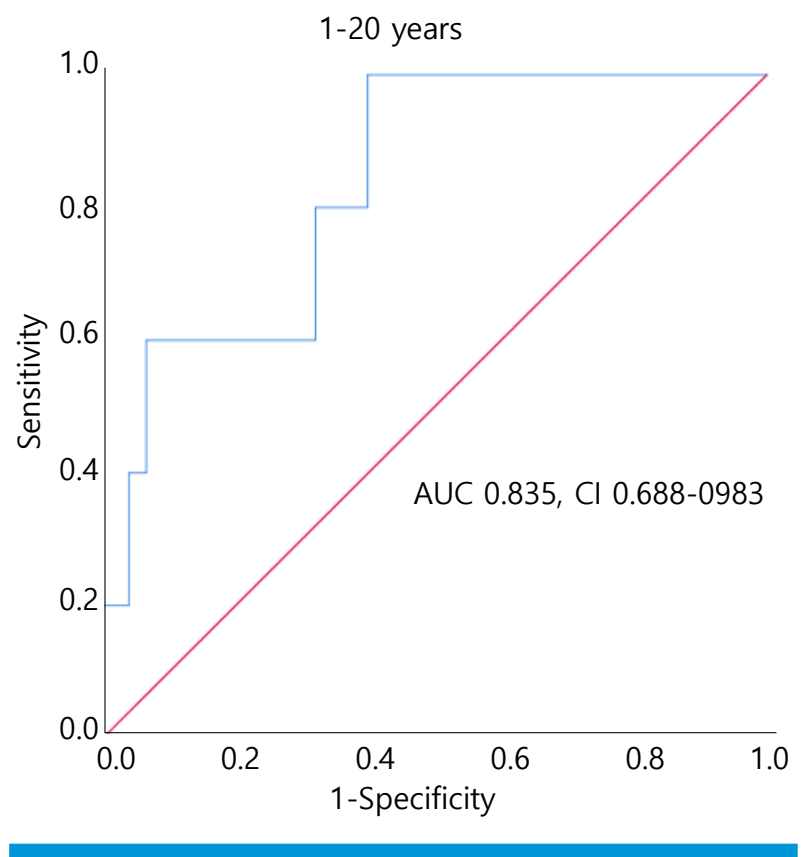

Fig. 3. Receiver operating characteristic $(\mathrm{ROC})$ curves analysis for UAGFR (mg/dL) (x-axis) versus UUACr (mg/mg) (y-axis); ability of UUACr to discriminate between children with and without hyperuricosuria; area under the ROC curve (AUC) statistic represents the probability of correctly classifying children with and without hyperuricosuria, (a) Total age group, (b) 1-20 age;. Cl, confidence interval; UAGFR, urine uric acid glomerular filtration rate; UUACr, urine uric acid creatinine ratio. 
16-20yrs old group.

\section{Discussion}

Uric acid arises as the final product of purine metabolism in the liver and intestine ${ }^{7,19)}$.

Factors involved in the renal excretion of uric acid include blood uric acid levels, enzymes involved in excretion, presence of drugs and the charactrestics of the urine ${ }^{19)}$. Purine metabolism abnormalities such as Lesch-Nyhan syndrome and Down syndrome are also known to increase uric acid excretion ${ }^{7}$. Further, the higher urine $\mathrm{pH}$, the higher effective circulating volume, the higher uric acid level of serum, the higher dietary purine or protein and fructose intake or the higher serum glucose level increase uric acid excretion. Also, the cellular break-down, or the vitamin C or vitamin B 12 intake are known as the increase of uric acid excretion. However, cytotoxic drugs, L-dopa and pyrazinamide decrease uric acid excretion ${ }^{20,211}$. In patients with hypertensive status and obesity, uric acid excretion is decreased ${ }^{20)}$. Therefore, subjects with hyper tension and obesity were excluded. Additionly it is known that excretion of uric acid decreases with age ${ }^{7-16,22)}$. It is known that there are regional differences according to diet and culture (Table 2) ${ }^{9-16,22)}$. It can be seen that even in the same country, there are large differences in the values, depending on the year of inspection ${ }^{10-11,14,15)}$.

This study presented the reference range and upper $2 \mathrm{SD}$ value for UUACr of arbitrary urine samples by age, in Korean children (Table 1). The highest value was shown in the 1-5-month group, and it decreased with increasing age. The reason for the decrease in uric acid excretion with increasing age is presumed as GFR increase and tubular maturational changes ${ }^{7,19)}$.

According to Kaufman et al, UUACr showed diurnal rhythm, which was low in the early morning hours and high in the afternoon hours, but the differences are not large. In addition, Hasday et al similarly reported that UUACr increased at night in the obstructive sleep apnea group, but in the normal group, UUACr decreased at night. Its difference was around $13 \%$. It was not large enough for statistical significance ${ }^{23)}$. In Öner et al's study, 24 hr UUACr showed no statistically significant difference from postprandial UUACr levels ${ }^{14)}$. Penido et al did not show any difference between fasting and non-fasting UUACr levels ${ }^{222}$. In this study, urine samples were obtained at arbitrary times in the morning and afternoon. regardless of the meal.

In this study, the UAGFR value showed a decreasing trend with increasing age, but there was no significant difference by age as in other reports ${ }^{24)}$. When the upper $2 \mathrm{SD}$ value of UAGFR in normal children was used as a diag. nostic criterion for hyperuricosuria, Staplton et al suggested UAGFR was $0.53 \mathrm{mg} / \mathrm{dL}$, and this study similarly came up with $0.54 \mathrm{mg} / \mathrm{dL}$, which were higher than $0.48 \mathrm{mg} / \mathrm{dL}$, according to Penido et $\mathrm{a}^{8,22)}$ (Table 2). As a presumptive factor for this difference, Zöllner et al suggested protein intake, but there seems to be a controversy regarding this ${ }^{25}$. At the time of the initial UAGFR study, when Stapleton's reference value was established, the United States Department for Agriculture suggested that the per capita meat consump. tion totaled to $80 \mathrm{~kg}$ in the $1960 \mathrm{~s}^{8,26)}$. Meat consumption per capita in Korea was $51.3 \mathrm{~kg}$ in 2019, when this study was conducted, which is still lower than that of the United

Table 2. Comparison of Studies Relating Uric Acid Excretion in Different Countries

\begin{tabular}{|c|c|c|c|c|c|c|c|c|c|c|}
\hline Nation & $\begin{array}{l}\text { Korean* } \\
\text { (this study) }\end{array}$ & $U_{S A^{8)}}$ & Taiwan") & Iranian ${ }^{11)}$ & Iranian ${ }^{10)}$ & Turkish $^{16)}$ & Turkish ${ }^{15)}$ & Switzerland ${ }^{14)}$ & $\begin{array}{l}\text { Northern } \\
\text { Indian }^{17)}\end{array}$ & Brazil| \\
\hline year & 2020 & 1983 & 1994 & 2015 & 2003 & 2009 & 2004 & 1999 & 1997 & 2002 \\
\hline (n) & 168 & 82 & 1,072 & 232 & 990 & 1306 & 483 & 384 & 258 & 125 \\
\hline \multicolumn{11}{|l|}{ UUACR (mg/mg), Mean+2SD } \\
\hline Total age & 0.72 & & 0.189 & & & & & & 0.48 & \\
\hline 7-10yrs & 0.73 & & 0.268 & 0.69 & 0.213 & 0.93 & 0.77 & 0.83 & & \\
\hline $11-14 y r s$ & 0.61 & & 0.109 & - & 0.107 & 0.62 & 0.66 & 0.65 & & \\
\hline $15-y r s$ & 0.47 & & 0.105 & - & - & - & & 0.59 & & \\
\hline UAGFR (mg/dL) Mean+2SD & 0.54 & 0.53 & & & & & & & 0.47 & 0.45 \\
\hline
\end{tabular}

*Age group: 6-9 years, 9-13 years, 13-16 years.

Abbreviations: UUACR, urinary uric acid creatinine ratio; UAGFR, uric acid glomerular filtration rate. 
States in the 1960s, but there is little difference in the UAGFR values of the two studies ${ }^{27}$. In addition, Penido et al observed that calorie intake and protein intake differed by age, but there was no change in $\mathrm{UAGFR}^{22}$. Across ethnicities, Sweid et al, study on North Indians showed no proportional relationship between protein diet and uric acid level ${ }^{16)}$. In other words, it seems that the similar or different UAGFR values by country cannot be explained only by high or low meat protein intake. It seems necessary to explain the difference in UAGFR values as per the differences in the study period, in the same country (Table 2).

Similar to previous studies, in this study, UAGFR values were not different by age group. According this, UAGFR could be used for diagnosis of hyperuricosuria. And in this study showed UAGFR and UUACr were in positively proportional relationship. So, we suggested that UUACr is used for screening test of hyperuricosuria without blood sampling. But it should be used carefully. Because UUACr values were decreased by grown-up.

This study can be considered as the first study to compare UUACr and UAGFR, to determine the diagnostic value of hyperuricosuria. The limitation of this study is that nutrition and diet evaluation was not conducted. The study also did not distinguish between fasting and non-fasting individuals. Further, it was a single institution study.

Thus, there should be further study considering nutrition and diet evalution. Also, in this study, we set the upper 2SD value UAGFR of normal children as hyperuricosuria. And through that, we obtained UUACr cut-off value. In fact, it is necessary to obtain uric acid values from children with abnormal uric acid metabolism to suggest a reference value of UUACr, as it shows high sensitivity and specificity diag. nostic criteria of uric acid metabolic diseases. And there should be more normal subjects enrolled to check cut-off value of each age groups.

\section{Acknowledgments}

This study was presented as a poster presentation at the 56th European Renal Association - European Dialysis and Transplant Association. Budapest, Hungary, 13-16 June 2019.

\section{Conflicts of interest}

No potential conflict of interest relevant to this article was reported.

\section{ORCID}

Hyowon Choi: http://orcid.org/0000-0002-2040-389X

Meekyung Namgoong: https://orcid.org/0000-00028156-8970

\section{References}

1. Arrabal-Polo MA, Cano-Garcia MDC, Arrabal-Martin M. Lithogenic activity as a factor to consider in the metabolic evaluation of patients with calcium lithiasis. Iran J Kidney Dis 2015;9:469-71.

2. Cillo AC, Cattini H, Boim MA, Schor N. Evaluation of lithogenic elements in urine of healthy newborns. Pediatr Nephrol 2001;16: 1080-3.

3. Hartung R. The significance of uric acid in calcium oxalate nephrolithiasis. MMW 1975;117:387-90.

4. La Manna A, Polito C, Marte A, lovene A, Di Toro R. Hyperuricosuria in children: clinical presentation and natural history. Pediatrics 2001;107:86-90.

5. Hodgkinson A. Uric acid disorders in patients with calcium stones. Br J Urol 1976:48:1-5.

6. Stapleton FB. Hematuria associated with hypercalciuria and hyperuricosuria: a practical approach. Pediatr Nephrol 1994;8:75661.

7. Stapleton FB, Linshaw MA, Hassanein K, Gruskin AB. Uric acid excretion in normal children. J Pediatr 1978;92:911-4.

8. Stapleton FB, Nash DA. A screening test for hyperuricosuria. J Pediatr 1983;102:88-90.

9. Chen YH, Lee AJ, Chen $\mathrm{CH}$, Chesney RW, Stapleton FB, Roy S. Urinary mineral excretion among normal Taiwanese children. Pediatr Nephrol 1994;8:36-9.

10. Safarinejad MR. Urinary mineral excretion in healthy Iranian children. Pediatr Nephrol 2003;18:140-4.

11. Kompani F, Gaedi Z, Ahmadzadeh A, Seyedzadeh A, Bahadoram $M$. Values of urinary mineral excretion in healthy Iranian. J Ped Nephrol 2015;3:26-30.

12. Marco RH, Gómez FN, Costa CM, Moreno JF, Vidal AP, Solanes JB. Excreción urinaria de calcio, magnesio, ácido úrico y ácido oxálico en niños normales [Urinary excretion of calcium, magnesium, uric acid and oxalic acid in normal children]. An Esp Pediatr 1988; 29:99-104. 
13. Matos V, Van Melle G, Werner D, Bardy D, Guignard JP. Urinary oxalate and urate to creatinine ratios in a healthy pediatric population. Am J Kidney Dis 1999;34:e1.

14. Öner A, Erdogan Ö, Çamurdanoglu D, Demircin G, Bülbül M, Delibas A. Reference values for urinary calcium and uric acid excretion in healthy Turkish children. Int Pediatr 2004;19:154-7.

15. Poyrazoğlu HM, Düşünsel R, Yazici C, Durmaz H, Dursun I, Şahin $H$, et al. Urinary uric acid: Creatinine ratios in healthy Turkish children. Pediatr Int 2009;51:526-9.

16. Sweid HA, Bagga A, Vaswani M, Vasudev V, Ahuja RK, Srivastava RN. Urinary excretion of minerals, oxalate, and uric acid in north Indian children. Pediatr Nephrol 1997;11:189-92.

17. Moriwaki Y, Yamamoto T, Takahashi S, Yamakita J, Tsutsumi Z, Hada T. Spot urine uric acid to creatinine ratio used in the estimation of uric acid excretion in primary gout. J Rheumatol 2001;28: 1306-10.

18. Williams K, Thomson D, Seto I, Contopoulos-loannidis DG, Ioannidis JP, Curtis S, et al. Standard 6: age groups for pediatric trials. Pediatrics 2012;129:S153-60.

19. Baldree LA, Stapleton FB. Uric Acid Metabolism in Children. Pediatr Clin North Am 1990;37:391-418.

20. Mantani N, Hoshino A, Ito K, Kogure T, Moridaira K, Sakamoto H, et al. Relationships among urine $\mathrm{pH}$, serum uric acid and pyuria in hospitalized elderly patients. Nihon Ronen Igakkai Zasshi 2004:41:542-555.

21. Grivna M, Průsa R, Janda J. Urinary uric acid excretion in healthy male infants. Pediatr Nephrol 1997;11:623-4.

22. Penido MG, Diniz JS, Guimarães MM, Cardoso RB, Souto MF, Penido MG. Urinary excretion of calcium, uric acid and citrate in healthy children and adolescents. J Pediatr (Rio J) 2002;78:15360.

23. Hasday JD. Noctural increase of urinary uric acid:creatinine ratio. A biochemical correlate of sleep-associated hypoxemia. Am Rev Respir Dis 1987;134:534-8.

24. Kaufman JM, Greene ML, Seegmiller JE. Urine uric acid to creatinine ratio-a screening test for inherited disorders of purine metabolism. Phosphoribosyltransferase (PRT) deficiency in X-linked cerebral palsy and in a variant of gout. J Pediatr 1968;73:583-92.

25. Zöllner N. Influence of various purines on uric acid metabolism. Bibl Nutr Dieta 1973:34-43.

26. Daniel CR, Cross AJ, Koebnick C, Sinha R. Trends in meat consumption in the USA. Public Health Nutr 2011;14:575-83.

27. Welfare MoHa. The Korean Nutrition Society. Dietary reference intakes for Koreans 2020 In: Welfare MoHa, editor. Sejong; 2020. 